\title{
Non-predicative verb forms in different system languages
}

\author{
Mostafa M. Keruly - Rasim R. Khusnutdinov
}

DOI: 10.18355/XL.2018.11.02.28

\begin{abstract}
The relevance of the issue is determined by the fact that the interdependence of languages is an actual and objective fact of reality, which cannot be ignored by linguists. The purpose of this paper is to carry out a comparative analysis of nonpredicative verb forms of the Russian and Turkish languages at the language level and their syntactic functions to reveal the degree of their similarity and difference as well as determine the nature of their relationship. The leading approach to the study of this issue is based on linguistic phenomena from the point of view of the Russian and Turkish languages with regard to theoretical and methodological positions adopted in Russian and Turkic studies. The findings of the paper can be used as a basis for further comparative study of other verb forms and grammatical categories, as well as parts of speech and word classes of the Russian and Turkic languages.
\end{abstract}

Key words: verb, non-predicative form, Turkish language, Russian language, participle

\section{Introduction}

This paper is presented within the framework of comparative linguistics. General tasks of a comparative study of languages, formulated by V.G. Gak, include the identification of convergences and divergences in the use of linguistic means by different languages as well as the definition of the characteristics of each language being compared (Gak, 1974). Comparative studies are directly related to non-native language teaching and translation theory. Such studies provide for typology to identify universals. B. de Courtenay (2003) emphasized that languages can be compared completely regardless of their kinship and various historical ties between them. One can always find the same properties, the same changes, the same historical processes and transformations in languages that are genetically, historically and geographically distinct from each other.

N.M. Shansky (1972) concluded that the typological, comparative-historical and contrastive study of the systems of Russian and native languages can be distinguished among the extremely important issues by its exceptional significance and priority, since it provides the key to the scientific solution of all the most important questions of the methodology of teaching Russian to foreigners (Shansky, 1972).

In this article, the Russian language is chosen as the basis for a comparative study. This choice of language is due to the degree of its study, the activity of its use, as well as the fact that non-finite verb forms in the Russian language have a more clearly defined character. The comparative study of different system languages is carried out within the framework of the current issues, the most important of which is the verb and the study of its multidimensional system.

Non-predicative (non-finite, non-conjugate) verbs or verbals are verb forms that do not have mood, tense, number, or person, i.e. they do not have the basic grammatical categories of the verb. They include infinitives, gerunds, participles, and adverbial participles (Bosque, 2014).

In Russian and Turkic studies, there is no special monographic research devoted to the comparative analysis of non-predicative verb forms in the Russian and Turkish languages. Comparative, comparative-contrastive or comparative-historical studies of these languages are of a general nature. At the same time, there is a limited number of materials from the Turkish language. The study of non-predicative verb forms in 
Turkic languages began simultaneously with the study of verb forms in the first grammar of Turkic languages. Fragmentary information about some ways of forming non-finite forms is found in earlier published grammar books and studies on the Turkish language.

Researchers expressed different views on the nature of participles and adverbial participles in Turkic languages. For example, some Turkologists study participles along with verbal nouns, considering them to have lost the meaning of the verb and turned into nouns and adjectives. Other researchers classify participles entirely as verb forms (considering them one of the derivatives of verb forms), nevertheless, referring to them in different ways: verbal-nominal forms, verbal nouns, participles. In Turkic studies, there are many works devoted to the study of participial forms in certain Turkic languages. They consider participles in almost all aspects (comparativetypological, comparative-historical, etc.). Thus, the main provisions regarding nonpredicative verb forms in Turkic languages were developed as early as in the last century. One way or another, the composition of participial and adverbial verb forms was presented, the infinitive was defined, and their basic constructions were developed. Undoubtedly, while some issues require additional study, others require a fundamentally different method of study. At the same time, the available material represents a certain basis for conducting comparative studies.

\section{Methodological Framework}

This work uses various methods, including those of comparison, description and component analysis, as well as such research techniques as analogy, opposition, observation, and generalization. The study of the material is based on the approach to linguistic phenomena from the point of view of the Russian and Turkish languages, with regard to theoretical and methodological positions adopted in Russian and Turkic studies.

\section{Results}

The issue addressed in this paper is partly terminological in nature, since researchers rely basically on the same properties of the considered forms despite all differences in their approaches. A wide interpretation of the composition of the verbal paradigm provides for a more holistic view of the verb and has the advantage of a systemic approach. Non-conjugate or non-finite, forms originate from certain verb stems. The main verb categories are common for both finite and non-finite verb forms, although they manifest themselves in the latter in a special way. In the Russian language, common verb categories (i.e. characteristic of all verb forms) include the categories of aspect and voice.

In addition to non-finite verb forms, verbal derivates are widely represented in the system of the considered languages - nouns, adjectives and adverbs formed from verb stems. Despite the fundamental difference between these lexemes and non-finite verb forms, they were occasionally put into consideration, since in comparative studies it is more important to express one or another meaning than a formal belonging to a particular part of speech (Heath, 1985).

In the course of comparison, it was determined that in addition to common features, the verb in both languages is characterized by distinctive properties, expressed mainly in syntactic and, to a lesser extent, structural features. The dynamics of these forms in the two languages is different.

In the considered languages, the non-finite verb form outside the word combination describes an action irrespective of mood, tense, person, or number.

The comparative study of non-predicative verb forms in the Russian and Turkish languages, their composition, structure, forms of expression and classification, as well

XLinguae, Volume 11, Issue 2, April 2018, ISSN 1337-8384, eISSN 2453-711X 
as the peculiarities of their use made it possible to reveal the level of similarities and differences in the forms of expression, as well as the syntactic functions of these verb forms.

The process of formation of the systems of non-predicative verb forms in each of the compared languages is the result of historical processes because the forms of these grammatical systems are based on long-standing forms, only some of them being new. Therefore, this process appears in dynamics. This explains why researchers of both Russian and Turkic languages, especially those who studied these languages as far back as the 19th century, did not discover some of non-predicative verb forms that exist in current linguistics. However, researchers who studied these languages in the mid- to late-19th century discovered much more uninflected verb forms. The reason for this was that some forms had already been developed appearing as full nonpredicative forms with their meaning and function.

The study conducted within the framework of comparing structural-semantic and functional features in the Russian and Turkish languages corresponds to the goal and tasks set in the work. The following significant findings were obtained in the research:

a) A thorough analysis of Russian and Turkic non-predicative verb forms was conducted;

b) The analyzed material was considered through the prism of structural, derivational, and functional-syntactic classifications;

c) Russian and Turkic non-predicative verb forms were analyzed in a comparativecontrastive aspect, with universal and specific features being revealed in the two languages.

Despite the difference in the structure of the analyzed languages, there are some correspondences in Russian and Turkish:

- in both languages, non-predicative verb forms are represented by the participle, the adverbial participle, and the infinitive. The form ending with $-M a$, considered in the Turkish language basically as a clipped infinitive form, is regarded as the name of an action in our study. Similar formations in the Russian language are nouns (verbal nouns);

- participles in both languages simultaneously possess the properties of both the adjective and the verb;

- in Russian and Turkish the participle in the sentence usually acts as a subordinate definition member - it fulfills the same role as the adjective in the sentence.

At the same time, in both languages, participles can take different syntactic positions in the sentence, while performing the functions of any member of the sentence. This ability is inherent in the participles of both languages due to their dual nature, which reveals the signs of the verb and the noun. Nevertheless, the participles of the Russian and Turkish languages can perform the role of the subject only under certain special conditions, i.e. in the context of substantiation. The participle in both languages is substantiated.

- Russian and Turkish adverbial participles perform mainly the circumstantial function in the sentence and the function of the non-finite predicate in the polypredicative sentence. In addition, Turkish adverbial participles can act as the finite predicate, combined with the auxiliary verb, being an important part of the compound predicate;

- the infinitive in both languages is of a dual nature: nominal and verbal;

- the infinitive as a non-finite verb form in both languages does not have the categories of number, tense, or mood.

A certain similarity of non-predicative verb forms in the Russian and Turkish languages is a natural result of the similarity in social reality and human experience as well as the universality of the categories of human thinking.

Along with universal features, almost mutually exclusive features were found in the studied languages: 
- in Russian the participle inflects for gender, while in Turkish, the participle, as any part of speech, does not have gender;

- Russian and Turkish languages have different tenses: present (gelen), past (geldik, gelmiş), future (gelecek) and present-future (gelir) in Turkish; present (уносящийся) and past (уносившиисся) in Russian;

- unlike in Turkish, in Russian the participle can be reflexive, formed from reflexive verbs;

- adverbial participles and adverbial constructions in the Russian language can be prepositive and postpositive in relation to the main verb, while in Turkish, they are always placed before the main verb;

- unlike in Russian, in the Turkish language the adverbial participle can be formed from any verb;

- unlike the Russian infinitive, the Turkish infinitive, as the noun, can be inflected for case;

- other infinitive verb forms that distinguish the Turkish language from Russian, are special action nouns - verb forms that stand somewhat closer to nouns than the infinitive. Russian verbal nouns semantically correspond to action nouns in the Turkish language. However, in Russian, this form represents verb constructions that have become nouns, while action nouns in the Turkish language are verb forms that combine nominal properties.

As for the syntactic functions of infinitive verb forms in Russian and Turkish, both divergences and convergences are observed here.

This study is based on the comparison of verb constructions: participles, adverbial participles, infinitives in the compared languages, and action nouns in Turkish. Each non-predicative form has its own peculiarities of derivation, formation, and functioning in the language. Proceeding from these peculiarities, the work revealed universal and unique features by language. The common feature for all forms is that they are a non-finite verb form.

Non-predicatives in the study were investigated in derivational, semantic, structural and functional aspects (Colombo et al., 2004).

The complex analysis made it possible to reveal the structural-semantic and functional-stylistic features of non-predicatives (participles, adverbial participles, infinitives in both languages, and action nouns - in Turkish) in Russian and Turkish.

The results of the comparative analysis of non-predicatives indicate that possible directions of the considered process have been determined and recorded in linguistics. Thus, the comparative study of Russian and Turkish non-predicative verb forms has shown that the systems of participles and adverbial participles in these languages are typologically similar in many respects. This is evidenced by the fact that almost every participle and adverbial participle form of the Russian language has its semantic equivalent in the Turkish language.

The syntactic functions performed by participles and adverbial participles usually coincide.

The revealed similarity between Russian and Turkish non-predicative verb forms is only typological. There are no material similarities. This indicates that Russian and Turkish non-predicative verb forms, despite being considered the most ancient verb forms, have been developed in these languages after the disintegration of the hypothetically common proto-language, if one assumes the existence of such a language.

The study of the infinitive in different system languages belonging to the Slavic group and the Turkic family-Oguz group, the identification of common and distinctive features as well as the peculiarities of the use of the infinitive can be used for its typological comparison in these languages.

XLinguae, Volume 11, Issue 2, April 2018, ISSN 1337-8384, eISSN 2453-711X 
The complex comparative description of the considered languages in terms of studying non-predicative verb forms allows for a better understanding of the structure of each language and an identification of typological convergences and divergences between these languages (Kuczaj, 1977).

The proposed method of the poly-aspect study of Russian and Turkish nonpredicatives as a complex and multifaceted linguistic object can be used in studying the non-finite verb forms of other different system languages.

General language tendencies can be seen in many features of non-finite verb forms of the compared languages - if not universal, but those that are often found in languages of the most diverse systems. These are, for example, the common origin of nonconjugated forms, and the processes of substantivization, adjectivization and adverbialization. These and many other facts emphasize that features of the Russian and Turkish languages have many general language tendencies.

\section{Discussion and Conclusions}

The issues of the grammar of participles were specifically addressed in the dissertation works and articles of E.A. Cowper (1995), G.L. Lewis (1967), K.E. Kiss, F. Kiefer and P. Siptár (2003), W.C. Dong and P. Jungyoung (2015), D. Creissels (2009).

The linguistic works devoted to the problems of participles mainly study their adjectivization. The problem of adjectivization was considered by many researchers, such as J.L. Boyer (1984), I. Rapp (2015), Ch. Kauschke, L.F. Renner and U. Domahs (2016), D. Embick (2004). The adjectivization of Russian participles was studied in a synchronous and diachronic aspect and in comparison with the adjectivization of participles in other languages, both Indo-European and languages of other language families.

A verb is a part of speech that expresses the grammatical meaning of an action, which functions primarily as a predicate. Considering the two parts of this definition in a general-typological aspect, one can see that the meaning of an action and the functioning as a predicate are not related to each other by a rigid logical connection. The word "primarily" itself means that, as a matter of fact, a verb can function not only as a predicate, and the grammatical meaning of an action can be expressed independently of the predicative function.

From the morphological point of view, a verb in many languages (including Russian and Turkish) is a complex system of grammatical forms. The complexity of this system is determined, first of all, by the fact that it is in verb forms that the so-called predicative categories (categories that are related to the content of the whole sentence such as tense, mood and person) are expressed. On the other hand, since a verb can act not only as a predicate, there can be special morphological mechanisms in the language that ensure the non-predicative use of the verb word.

Accordingly, the framework of the verbal lexeme in different languages combines not only predicative forms, i.e. forms used as a predicate, but also the entire system of non-predicative forms, described by such terms as the infinitive, the participle, the adverbial participle, the gerund, the gerundive, the supine, the masdar, etc.

The center of the verb system, as recognized by almost all researchers, is finite forms that have a full set of verb morphological categories and perform the syntactic role of a predicate. Non-finite forms are treated as peripherals, and sometimes they are removed from the verb system, acquiring a different interpretation. Such a decision is more than traditional. It is known that the ancient Greeks, creators of the Alexandrian grammar system, which formed the basis of traditional grammar, considered the participle an independent part of speech. 


\section{Recommendations}

This article is of interest for specialists who teach the Turkish language and Turkish grammar and for those who study non-predicative verb forms in different system languages.

\section{Acknowledgements}

The work is performed according to the Russian Government Program of Competitive Growth of Kazan Federal University.

\section{Bibliographic references}

BOSQUE, I. 2014. On Resultative Past Participles in Spanish. In: Catalan Journal of Linguistics, vol. 13, pp. 41-77. ISSN: 1695-6885.

BOYER, J.L. 1984. The classification of participles: a statistical study. In: Grace Theological Journal, vol. 5, n. 2, pp.163-179. ISSN: 0198-666X.

COLOMBO, L. - LAUDANNA, A. - DE MARTINO M. - BRIVIO, C. 2004.

Regularity and/or consistency in the production of the past participle? In: Brain and Language, vol. 90, n. 3, pp. 128-142. ISSN: 1090-2155.

COWPER, E.A. 1995. English Participle Constructions. In: Canadian Journal of Linguistics, vol. 40, n. 1, pp. 1-38. ISSN: 0008-4131.

CREISSELS, D. 2009. Principles and Finiteness: The Case of Akhvakh. In: Linguistic Discovery, vol. 7, n. 1, pp. 106-130. ISSN: 1537-0852.

DE COURTENAY, B. 2003. New Illustrated Encyclopedia. Moscow: The Great Russian Encyclopedia. ISBN: 5-85270-195-5.

DONG, W.C. - JUNGYOUNG, P. 2015. Supplementive Participle Clauses in Science Journal Papers by Korean Graduate Students. In: The journal of Asia TEFL, vol.12, n. 4, pp. 1-36. E-ISSN: 2503-2569.

EMBICK, D. 2004. On the Structure of Resultative Participles in English. In: Linguistic Inquiry, vol. 35, n. 3, pp. 355-392. ISSN: 0024-3892.

GAK, V.G. 1974. Comparative study of languages and linguistic typology. In: Russian Language Abroad, n. 3, pp. 40-45. ISSN: 0131-615X.

HEATH, J. 1985. Proto-Northern Uto-Aztecan Participles. In: International Journal of American Linguistics, v. 51, n. 4, pp. 441-452. E-ISSN: 1545-7001.

KAUSCHKE, Ch. - RENNER, L.F. - DOMAHS, U. 2016. Past participle formation in specific language impairment. In: International journal of language and communication disorders, vol. 52, n. 2, pp. 168-183. ISSN: 1460-6984.

KISS, K.E. - KIEFER, F. - SIPTAR, P. 2003. Új magyar nyelvtan. Budapest: Osiris Kiadó. ISSN 1218-9855.

KUCZAJ, S.A. 1977. The acquisition of regular and irregular past tense forms. In: Journal of Verbal Learning and Verbal Behavior, vol. 16, n. 5., 352-366. ISSN: 00225371.

LEWIS, G.L. 1967. Turkish Grammar. Oxford: Oxford University Press. ISBN 0-19815838-6.

RAPP, I. 2015. On the Temporal Interpretation of Present Participles in German. In: Journal of Semantics, vol. 32, n. 3, pp. 477-523. ISSN: 01675133.

SHANSKY, N.M. 1972. Lexicology of the modern Russian language. Moscow: Prosveshchenie. ISBN 978-5-397-00704-7.

XLinguae, Volume 11, Issue 2, April 2018, ISSN 1337-8384, eISSN 2453-711X 
Words: 3286

Characters: 21881 (12,15 standard pages)

Senior lecturer Mostafa M. Keruly, Master

Institute of International Relations, History and Oriental Studies

Kazan (Volga Region) Federal University

1/55 Pushkin Str.

420008, Kazan,

Russia

mmkeruly@gmail.com

Assistant Rasim R. Khusnutdinov, PhD of Economic Sciences

Leo Tolstoy Institute of Philology and Intercultural Communication

Kazan (Volga Region) Federal University

1/55 Pushkin Str.

420008, Kazan,

Russia

knikazan@gmail.com 